\title{
Selective Oxidation Catalysis Opportunities and Challenges
}

\section{Review Article}

Author(s):

Hermans, Ive; Spier, Eyal S.; Neuenschwander, Ulrich; Turrà, Natascia; Baiker, Alfons

Publication date:

2009

Permanent link:

https://doi.org/10.3929/ethz-b-000015544

Rights / license:

In Copyright - Non-Commercial Use Permitted

Originally published in:

Topics in Catalysis 52(9), https://doi.org/10.1007/s11244-009-9268-3 


\title{
Selective Oxidation Catalysis: Opportunities and Challenges
}

\author{
Ive Hermans - Eyal S. Spier • Ulrich Neuenschwander • \\ Natascia Turrà $\cdot$ Alfons Baiker
}

Published online: 1 May 2009

(C) Springer Science+Business Media, LLC 2009

\begin{abstract}
This contribution discusses some aspects crucial for designing optimal and sustainable oxidation processes. The catalyst, although at the heart of the system, is only one decisive design parameter amongst many others. Indeed, an interdisciplinary approach is required to improve existing processes, but also to rationally and systematically access opportunities for oxidation research on renewable feedstock compounds.
\end{abstract}

Keywords Renewable feedstock · Process viability · Activation $\cdot$ Partial oxidation

\section{Introduction}

Within the broad domain of oxidation chemistry, oxygenations (i.e. the take-up of oxygen) constitute an important and diverse sub-class, including such differing processes as metal corrosion, deterioration of biological and man-made materials, combustion, and artificial partial oxidation [1]. The last area refers to the selective introduction of functional groups for example in alcohols, aldehydes and carboxylic acids, without over-oxidizing the desired product. Such oxygenated molecules are used as building blocks in

I. Hermans $(\varangle)$ · E. S. Spier · U. Neuenschwander · N. Turrà ·

A. Baiker

Department of Chemistry and Applied Biosciences,

Institute for Chemical and Bio-Engineering,

ETH Zurich, Wolfgang-Pauli-Strasse 10,

HCI E123, 8093 Zurich, Switzerland

e-mail: hermans@chem.ethz.ch nearly all branches of chemical industry, ranging from polymer synthesis to medicinal chemistry [2,3]. This industrial interest explains the massive increase in the number of scientific publications in the later half of the 20th century (Fig. 1) (ISI Web of Knowledge). The importance of oxidations, coupled with the obvious need for improvement, especially with regards to process sustainability, has transported this domain to the forefront of chemical and chemical engineering research.

Usually a process-tailored catalyst is required to obtain the desired product in an economically acceptable yield $[1,3]$. One of the reasons is the higher oxidizability of the partial oxidation products, compared to the parent substrates, leading to an inherent selectivity problem. Partial oxidations are therefore considered a scientific challenge with direct industrial relevance. Optimizing the selectivity should be considered as the most important goal. Preventing the formation of waste is indeed the first objective of sustainable chemistry $[4,5]$. Although in principle both homogeneous and heterogeneous catalysts can be used to achieve this goal, usually solid catalysts are preferred because of easy handling (viz. recycling) and downstream processing considerations $[6,7]$.

Despite decades of academic and industrial research, oxidations still remain poorly understood chemical transformations. The reason for this is the fact that a successful oxidation process involves a complex interplay of many parameters. Whereas some of these parameters are fixed and determined by the nature of the substrate (viz. the intrinsic chemistry and reactivity of the involved functional groups), some parameters can be adjusted to optimize the performance (viz. the catalyst composition, the source of oxidizing species, the mass and heat transfer as determined by the reactor concept and activation of the reaction by heat, electrical current or light of appropriate wavelength). 


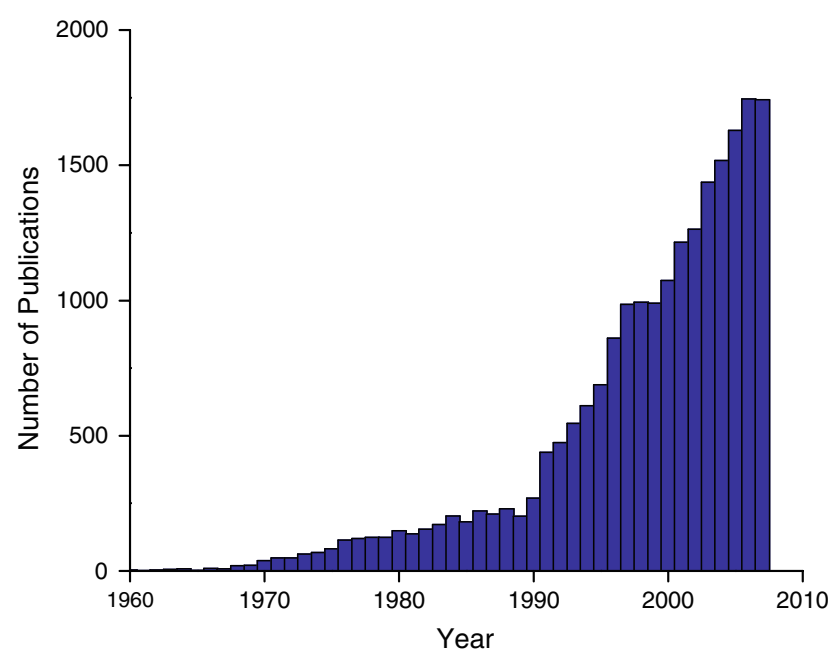

Fig. 1 Number of Publications on selective oxidations in the last decades

There exists a nearly infinite number of materials which can be used as oxidation catalyst, ranging from immobilized metal complexes over, (mixed) oxides, and noble metals to microporous solids [6, 7]. However, it is important to realize that it is not only the catalyst which determines the overall outcome; rather the oxidative transformation should be optimized at a process level, demanding a multidimensional approach. It is the purpose of this mini-review to seek out the future potential of oxidation catalysis from this multi-dimensional view point, within the framework of green chemistry (Fig. 2), rather than to give a complete overview of the domain.

\section{Feedstock}

A first question which comes to mind when looking into the future of oxidation catalysis is the origin of the feedstock: what will the future starting materials of interest be? The outcome of this question will mainly depend on the interplay of the parameters shown in Fig. 3. Whereas the cost of a certain feedstock is inversely proportional to its availability, it is directly correlated with its potential scope (cfr. propene versus propane). The available technology to produce/harvest and process/use the feedstock is obviously another parameter determining its price. Especially for bulk processes it is important to have a reliable feedstock of constant quality and price. Fluctuating purity of the feedstock will increase the cost of pre-process purification steps. For fine chemical processes with high value-addition, (small) fluctuations in the feedstock price can be absorbed more efficiently.

In the past decades, many oxidation processes have been developed for upgrading hydrocarbons which ultimately all originate from crude oil, via well established petrochemical pathways [1-3]. Indeed, crude oil used to be a cheap and abundant feedstock. Some examples of important industrial oxidation processes are listed in Table 1. Many of the oxygenated products are used for the synthesis of goods which have become indispensable in our present society (viz. all sorts of polymers). Due to the shrinking reserves of crude oil, chemists are focusing onto the optimization of existing processes and the design of alternative routes, starting from more abundant, and thus cheaper, feedstock compounds. One noticeable trend is for instance to focus
Fig. 2 Important parameters for the design of selective oxidation processes within the framework of green chemistry

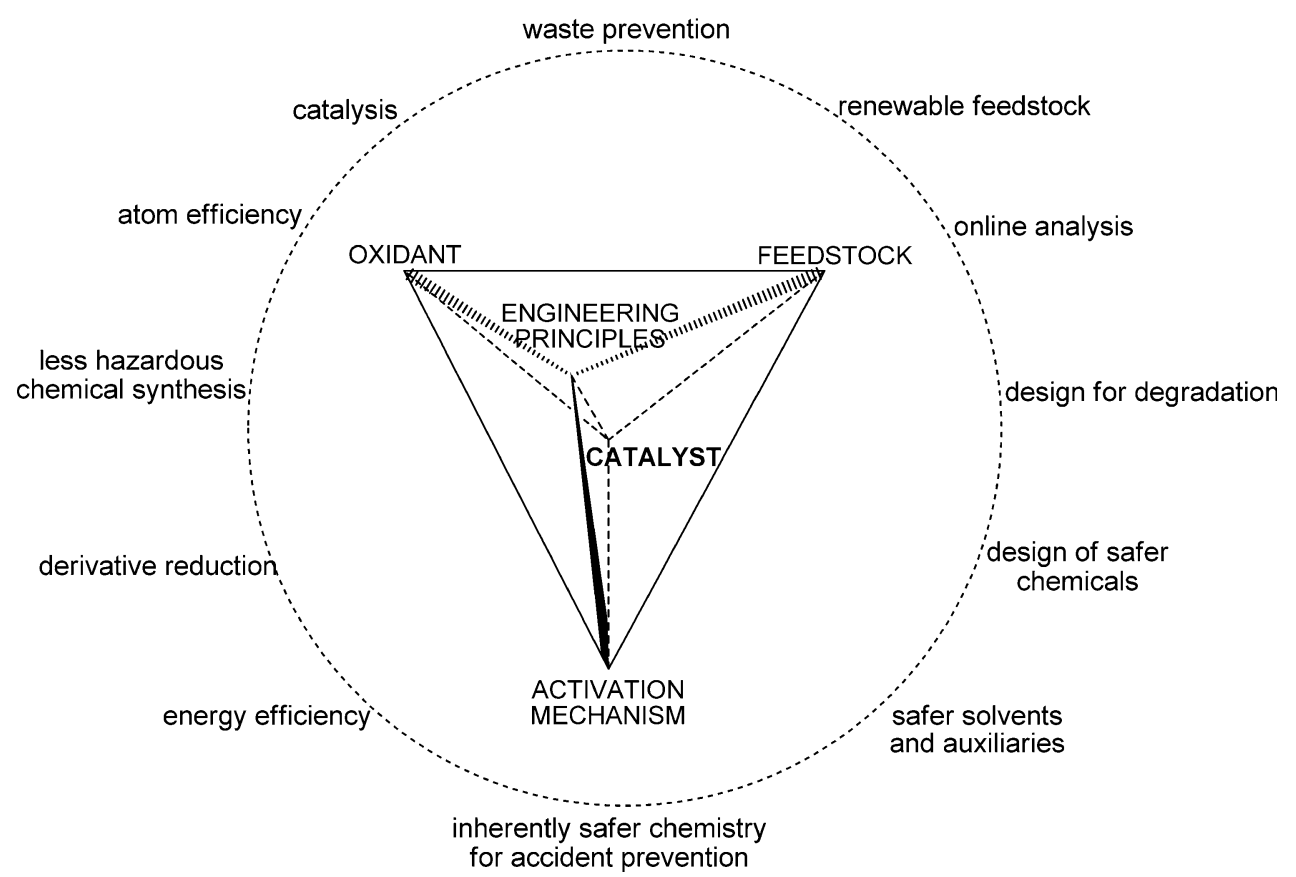




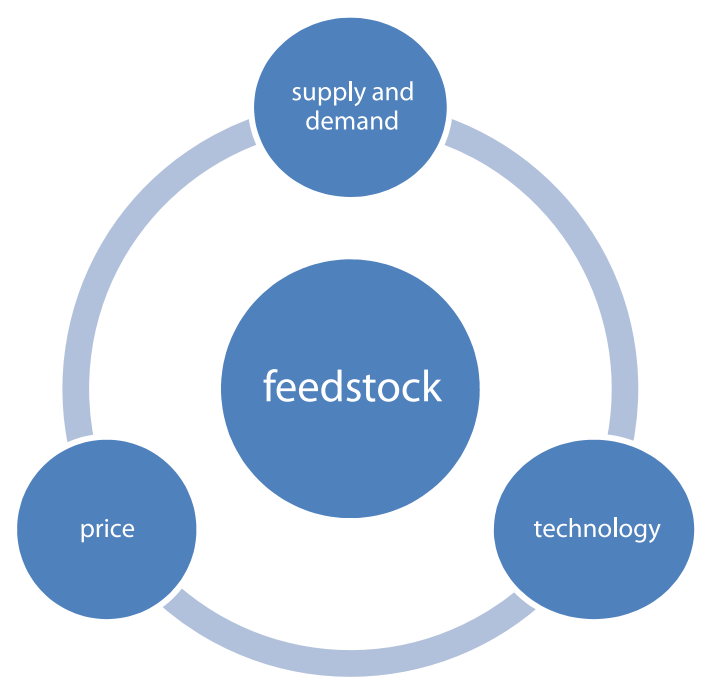

Fig. 3 Important feedstock parameters

Table 1 Important oxidation processes of petrochemical feedstock molecules

\begin{tabular}{lll}
\hline Substrates & Product & Oxidant/Catalyst \\
\hline Ethylene & Ethylene oxide & Air/Ag on support \\
Propene & Propylene oxide & $\mathrm{H}_{2} \mathrm{O}_{2} / \mathrm{TS}-1$ \\
Propene & Acroleine & $\mathrm{Air} / \mathrm{MoO}_{3} ; \mathrm{Bi}_{2} \mathrm{O}_{3} ; \mathrm{WO}_{3}$ \\
Methanol & Formaldehyde & Air/Ag or $\mathrm{MoO}_{3} ; \mathrm{Fe}_{2} \mathrm{O}_{3}$ \\
$p$-Xylene & Terephtahlic acid & Air/Co, Mn, $\mathrm{Br}$ \\
Butane & Maleic anhydride & Air $/ \mathrm{V}_{2} \mathrm{O}_{5} ; \mathrm{MoO}_{3} / \mathrm{Al}_{2} \mathrm{O}_{3}$ \\
\hline
\end{tabular}

research on utilizing alkanes rather than alkenes [8-13]. Also the reduction of unit operations or entire process steps is currently the focus of research. It would for instance be of great value to convert cyclohexane or $n$-hexane to adipic acid or caprolactame in one single step, justifying the research efforts in this direction [14-21]. All these current approaches aim for a more efficient use of our limited crude oil resources. It should however be acknowledged, that the reduction of process steps is eventually limited by the intrinsic reactivity of the involved chemicals.

A possibility to save crude oil on a larger scale would be the valorization of methane from various abundant fossil resources, such as natural gas and coal. Moreover, on the long run, methane could also be produced via biogas, generated by fermentation of organic matter [22]. Also methane hydrates, found in vast quantities at the sea floor, are a potential future source of methane. Rather than cracking large molecules in petroleum, this gas feedstock demands the development of chemical tools to construct larger building units from this $\mathrm{C} 1$ compound ("gas-toliquid"). Several paths are being intensively explored, e.g.: (i) the one step oxidation of methane to methanol, (ii) oxidative and non-oxidative coupling of methane, and (iii) Fischer-Tropsch synthesis of larger hydrocarbons from syngas, generated from methane [23, 24]. Direct oxidation of methane to methanol, avoiding the intermediate step of synthesis gas production, is a great scientific challenge. Indeed, the $\mathrm{C}-\mathrm{H}$ bonds in methane are very strong $\left(105 \mathrm{kcal} \mathrm{mol}^{-1}\right)$, making it a rather inert feedstock. Therefore, highly reactive radical or ionic species are often used to cleave the $\mathrm{C}-\mathrm{H}$ bond, however, causing significant over-oxidation of the desired methanol (and formaldehyde). In an alternative approach, the $\mathrm{C}-\mathrm{H}$ bond can be activated by a reactive metal complex of, e.g., Pt without the involvement of free radicals, carbocations or carbanions, generating $\mathrm{M}-\mathrm{R}$ intermediates [25-30]. These $\mathrm{M}-\mathrm{R}$ species can be selectively converted to oxygenated compounds. Unfortunately these reactions take place under rather harsh (viz. acidic) conditions. Moreover, the electrophilic intermediates are susceptible for inhibition by water and products. At present, organometallic chemists are therefore trying to activate $\mathrm{C}-\mathrm{H}$ bonds by electropositive low-valent metal complexes, generating nucleophilic M-R species to overcome this problem [31]. So far, however, no satisfying catalytic system could be developed. Nevertheless, if one succeeds in producing methanol in a sustainable way, methanol-to-olefin technology could provide us with various chemically significant molecular building blocks [32]. The same holds true for Fischer-Tropsch chemistry, starting from (methane-generated) syngas [33]. At the moment, it appears that Fischer-Tropsch technology would have more potential, provided the lifetime of the catalyst could be increased and the $\mathrm{C}_{n}$ product distribution could be controlled more effectively. Eventually it is hoped, that these emerging processes will allow us to (re)construct the crucial building block molecules obtained at present from crude oil.

In a parallel, but different approach, the suitability of renewable resources as chemical feedstock is being intensively investigated [34-36]. While at a first glance, the use of bio-derived substances for chemical syntheses seems to be wholly beneficial, the use of biomass as a chemical substrate introduces a new level of complexity; it is socially, ethically and finally also economically unacceptable to allow feedstock for chemical building blocks to compete with global food demands [37]. Nevertheless, even non-edible resources open up countless possibilities. Taking this into account, one should formalize the fundamental question associated with renewable feedstock:

Which routes may take us now, or in the near future, as simply as possible, from renewable resource to value added product, thus saving fossil resources? 
To answer this question, several factors should be taken into consideration. Indeed, according to Rostrup-Nielsen, success relies on doing the right thing at the right time in the right way (the so-called $\mathrm{R}^{3}$ rule) [38].

First of all, the alternative feedstock should be able to satisfy a significant fraction of the product demand (doing the right thing). If not, one should wonder if it is worthwhile pursuing this drop-in-the-ocean route. Another determining parameter which should be considered is the value-addition which can be created through a certain process (at the right time). This parameter rationalizes for instance why investors would still be interested in a process with a small absolute mass impact, but with a high financial benefit. Moreover, the product should be synthesized in the right way: the transformation should be as simple as possible. It is clear that the transformation of methanol to formaldehyde is less complicated on a molecular level than the conversion of cellulose to fine chemicals. This complexity can be roughly taken into account by considering the ratio of the sum of molecular weights (MW) of the product(s) and reactants(s), $\frac{\sum_{i} \mathrm{MW}_{X i}}{\sum_{j} \mathrm{MW}_{Y i}}$, where the subscripts $X$ and $Y$ represent the reactants or products in such a way that the ratio is $\leq 1$. It is the product of these three parameters which will determine how viable a certain production strategy is, and hence which processes should get research priority. Therefore we may roughly quantify the viability $\Phi$ as the product of the factors indicated in Eq. 1:

$$
\begin{aligned}
\Phi= & \frac{\text { Availability of Feedstock }}{\text { Demand of product }} \cdot \frac{\text { Unit price of product }}{\text { Unit price of Feedstock }} \\
& \cdot \frac{\sum_{i} \mathrm{MW}_{X i}}{\sum_{j} \mathrm{MW}_{Y i}}
\end{aligned}
$$

Note that $\Phi$ represents a best case scenario, assuming $100 \%$ yield. The availability and demand can be expressed in mole carbon/time, energy/time, or any other dimension which may be applied to a particular process. Using these basic parameters (demand and availability, feedstock and product cost, and the molecular weights) it is possible to estimate roughly, the viability and significance of a potential process, based solely on the feedstock and product properties, without having to enter into any details concerning the actual production system. Although the viability does not in itself reveal anything about the realizability or sustainability of a system, it allows the quick and simple comparison of a variety of systems, based on their realistic significance. As an example, Table 2 summarizes the viability of several existing processes, situated in bulk/commodity as well as in fine chemistry.

It is proposed, that the preliminary estimation of a processes' viability be performed as follows:
Table 2 Parameters determining the viability $(\Phi)$ of several existing processes, based on a conservative estimate according to Eq. 1

\begin{tabular}{llc}
\hline Feedstock & Product & $\Phi^{\mathrm{a}}$ \\
\hline Benzene + propene & Styrene & $1-2$ \\
$p$-Xylene & Terephthalic acid & $1-5$ \\
Methanol & Formaldehyde & $2-10$ \\
Sulfur & Sulfuric acid & $5-20$ \\
Hydrogen & Ammonia & $5-20$ \\
Propene & Propylene oxide & $10-20$ \\
Ethene & Ethylene oxide & $10-20$ \\
Benzene & Maleic anhydride & $20-30$ \\
Propylene & Acrylic acid & $20-80$ \\
Butane & Maleic anhydride & $100-200$ \\
Methane & Methanol & $100-200$ \\
3-Methylpyridine & Niacin (vitamine B3) & $0.5-2.0$ \\
Salicylic acid & Aspirin & $10-20$ \\
Lignin & Vanillin & $300-600$ \\
\hline
\end{tabular}

${ }^{\text {a }}$ Using the mole fractions

$\Phi \gg 1$ : highly viable process

$\Phi \approx 1$ : viable process

$\Phi \ll 1$ : possibly viable process

It is important to realize that $\Phi$ does not take into account the full complexity or yield of the process step(s), nor the sustainability and represents the situation at a certain moment in time. As such it cannot replace a thorough case-by-case evaluation of all the significant parameters. It is indeed possible, for $\Phi$ to show potential for a process which, upon further evaluation, is clearly technically unfeasible or environmentally unsound. In addition, there are several processes which will show very low viability while being necessary, such as the oxidation of highly toxic $\mathrm{CO}$ to $\mathrm{CO}_{2}$, which has low toxicity but is detrimental due to its contribution to the greenhouse effect.

The viability index should rather be understood as an answer to the fundamental, albeit hypothetical question: "Given a particular feedstock A, and one or more suggested products arising from $\mathrm{A}$, how viable is a process to transform this feedstock into any one of the suggested products at $100 \%$ efficiency?" Keeping this question in mind while analyzing the various paths leading away from the feedstock, allows a quick prioritization of those paths.

This principle may be illustrated using the example of glycerol. Glycerol, a by-product from bio-diesel production, is an example of a non-edible bio platform molecule. Generally speaking, many interesting products can be obtained from glycerol, not only by oxidation but also hydrogenation and dehydration [39-41]. Some of the proposed routes are summarized in Table 3, ordered according to the viability index of the process. Clearly there is not enough glycerol available to cover the complete need for 
Table 3 Products which can be obtained from glycerol, ordered according to the viability index of the process, based on a conservative estimate

\begin{tabular}{ll}
\hline Product & $\Phi^{\mathrm{a}}$ \\
\hline Ethanol & $(1-10) \times 10^{-5}$ \\
Citric acid & $0.1-1.0$ \\
Acrylic acid & $0.1-2.0$ \\
Propylene Glycol & $0.1-2.0$ \\
Acrolein & $1-5$ \\
Epichlorhydrin & $1-5$ \\
1,3-propane diol & $20-50$ \\
\hline
\end{tabular}

${ }^{a}$ Using the mole fractions

all C3 products used today. Therefore one should make a rational decision what to do with the glycerol. According to $\Phi$, the synthesis of 1,3-propane diol would be the most viable route, mainly because of its high value (building block for polyesters). However, looking more carefully at this reaction, it turns out that the proposed route is a multistep process in which glycerol is first converted to acrolein which, after the addition of water, is hydrogenated to 1,3-propane diol. In a multistep process, the overall viability is clearly limited by the least attractive step. Nevertheless, the numbers in Table 3 explain why, for instance both Solvay Biochemicals and Dow Chemical are planning to open world-scale glycerol-to-epichlorohydrin plants in 2010. Very important to realize here is however that the viability calculations were performed with the current production and price levels. In case of glycerol, the price is highly dependent on the bio-diesel demand, a parameter which is affected by the current socio-political situation. Depending on how the fuel market will develop, the feasibility of glycerol as a feedstock might change. Indeed, all things considered, bio-diesel is only a drop-inthe-ocean solution and alternative fuel sources must be sought to meet our increasing demands [42-51]. Therefore one should carefully judge if one wants to make profound changes early in the chemical value chain, such as using glycerol for the production of bulk intermediates.

The problem of fluctuating feedstock prices (and quality) is indeed a rather general problem for renewable platform molecules, making them at the moment less attractive/reliable on a bulk scale. Therefore people are also looking into alternative possibilities, such as the conversion of bio-mass to syngas or pyrolysis oil using those intermediates to rebuild the classical chemicals and fuels [34-36, 42-51]. This approach could indeed buffer price fluctuations and decouple the downstream processes from the choice of feedstock. One should not underestimate this consideration as most of the companies would like the renewable feedstock to be as compatible as possible with the existing infrastructure. On the other hand, in the field of fine chemicals, value addition and the process flexibility (viz. batch production) is normally very high, implying that this field could more safely withstand the strains and pressures of fluctuating feedstock prices. Consequently, non-edible, easily obtainable resources which can be readily functionalized to molecules which are difficult to obtain in a "classical" way, are more suitable for these applications than for use in bulk chemistry processes. For instance, the oxidation of the primary $\mathrm{C}-\mathrm{H}$ bond in glycerol yields subsequently glyceraldehyde and glyceric acid whereas the oxidation of the secondary $\mathrm{C}-\mathrm{H}$ bond can yield dihydroxyacetone; oxidation of both one primary and a secondary C-H bond yields hydroxyl pyruvic acid (Fig. 4) [39-41]. Currently these compounds only have a small market because of their high price, due to the fact that they have to be prepared by enzymatic reactions. Several catalytic systems, based on supported palladium and platinum have been proposed for the direct aerobic oxidation of glycerol. The selectivity can be tuned by promotion of the noble metal catalyst with bismuth or by the $\mathrm{pH}$ [39-41]. Recently, promising results have also been shown for the glycerol oxidation over supported gold particles [52].

Terpenes such as limonene and $\alpha$-, $\beta$-pinene can easily be obtained from coniferous trees and citrics and represent another interesting class of bio-platform compounds. Oxidation of these isoprene-like molecules can take place via epoxidation or allylic oxidation [53]. For instance the autoxidation of $\alpha$-pinene has attracted attention because the verbenone allylic oxidation product is used for insect control and as a raw material in the synthesis of taxol, an important therapeutic agent. At the moment one is however not yet able to tune the reaction conditions to get control over both channels using $\mathrm{O}_{2}$ as the oxidant. A deeper understanding of the role of the catalyst (viz. identifying the reactive intermediates) should in principle allow targeting either epoxidation or allylic oxidation in a selective way. In this context, the potential of in situ studies combined with a computational support cannot be over-emphasized [54-66].

The conclusions of this analysis can be summarized as follows:

- Renewable resources for the production of chemicals or fuels must not stand in competition with existing vital applications. Possibly one could apply Maslow's hierarchy of needs for prioritization purposes [67].

- It seems easier and economically more reliable to use bio-platform molecules with currently fluctuating availability and price for relatively small scale applications with high value addition (e.g. fine chemicals and functional materials), rather than for bulk processes.

- Research to improve classical routes to bulk/commodity chemicals should not be given up. Indeed, if one manages to convert sustainably-produced-biomass into classical 
Fig. 4 Oxidation products of glycerol<smiles>O=CC(O)CO</smiles><smiles>OCC(O)CO</smiles><smiles>CCC</smiles><smiles>O=C(CO)CO</smiles><smiles>O=C(O)C(O)CO</smiles><smiles>CCCCOC(=O)OCC(=O)C(=O)O</smiles><smiles>O=C(O)C(O)C(=O)O</smiles>

tartronic acid<smiles>O=C(O)C(=O)C(=O)OCCOCCO</smiles>

building block chemicals, a lot of the downstream valuechain will remain unchanged. An additional advantage of this approach would be that fluctuations in the availability and quality (and consequently the price) of the renewable resources could be leveled off in the production of bio-syngas and/or bio-oil.

So in the end one could establish two types of platform molecules: the classical building blocks as we know them today in chemical industry, and some selected bio-platform molecules which are readily obtained from nature and can be easily converted to value-added products (Fig. 5). Clearly, the technology to convert renewable resources (e.g. cellulose) to syngas or pyrolysis oil, needs to be developed (further). Alternatively one could also combine both types of platform molecules; an already available commercial example is for instance Ecovio ${ }^{\circledR}$ introduced to the market by BASF in early 2008 (www.ecovio.com) [68]. This polymer contains $55 \mathrm{wt} \%$ of an aliphatic-aromatic copolyester and $45 \mathrm{wt} \%$ of renewable polylactic acid (PLA).

Finally, the scarcity of resources (be they fossil or renewable) has provided, and will continue to provide an ever increasing incentive for the development of efficient selective oxidation processes [69].

\section{Oxidation Agent}

In the course of time, many oxidation agents have been used for selective oxidations. Figure 6 gives an overview of the most common oxidants and orders them according to increasing environmental friendliness.

As every oxidation requires a stoichiometric amount of oxidant, the use of high molecular mass species is highly waste-producing. One technique to assess the environmental pressure caused by a chemical process is the Efactor, proposed by Roger Sheldon [70-73]. This number gives the weight of waste or undesirable by-product divided by the weight of the desired product. Especially for fine chemicals and pharmaceuticals, the average E-factors are rather high, i.e., 5-50 and 25-100, respectively. Although useful, the E-factor does not take into account the nature of the waste. Indeed, in the case of classical textbook oxidations with for instance $\mathrm{K}_{2} \mathrm{Cr}_{2} \mathrm{O}_{7}$, the waste is toxic. One of the reasons that such sophisticated oxidants as pyridinium chlorochromate (PCC) are still in use (especially in fine chemical synthesis) is their high activity and selectivity.

Another widespread oxidant is $\mathrm{HNO}_{3}$, used for instance in the synthesis of nicotinic acid (vitamin B3) by oxidation of 5-ethyl-2-methylpyridine. Nitric acid is however not only used for fine chemical synthesis, it is also used for oxidizing cyclohexanol/cyclohexanone (KA-oil) to adipic acid, a building block of nylon-6,6. A disadvantage of $\mathrm{HNO}_{3}$ based oxidations is the fact that a stoichiometric amount of $\mathrm{NO}_{x}$ and $\mathrm{N}_{2} \mathrm{O}$ is produced. Although not always acknowledged in the scientific literature, $\mathrm{HNO}_{3}$ can normally be regenerated from $\mathrm{NO}_{x}$ in an associated $\mathrm{HNO}_{3}$ production plant [74]. Therefore, $\mathrm{HNO}_{3}$ can be considered 
Fig. 5 Evolution of a classical fossil feedstock to the future oleo feedstock

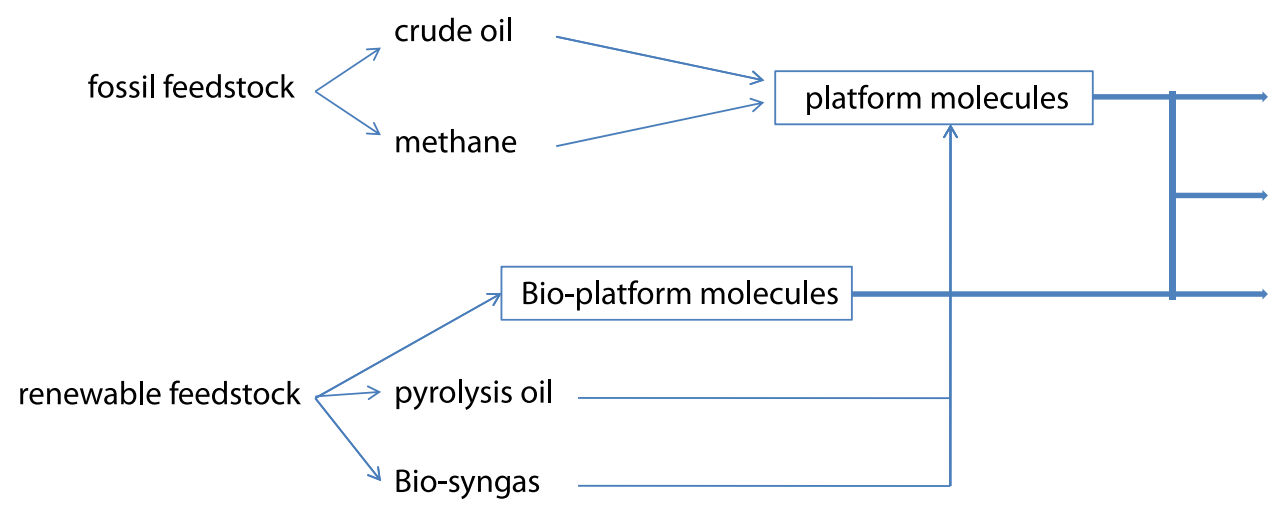

\section{$\mathrm{K}_{2} \mathrm{Cr}_{2} \mathrm{O}_{7}$, pyridiniumch
$\mathrm{HNO}_{3}, \mathrm{~N}_{2} \mathrm{O}$
$t$-butylhydroperoxide
$\mathrm{H}_{2} \mathrm{O}_{2}$
$\mathrm{O}_{2}$}

Fig. 6 Shift from environmentally harmful oxidants to oxygen

a carrier of activated oxygen. However, $\mathrm{N}_{2} \mathrm{O}$, a severe greenhouse gas, cannot be recycled and needs to be destroyed, either catalytically, or thermally. Some time ago, it was recognized that rather than decomposing the nitrous oxide, one could also use it as a sustainable oxidant, producing only $\mathrm{N}_{2}$ as a harmless by-product. Many interesting systems have been developed for using $\mathrm{N}_{2} \mathrm{O}$, such as the direct thermal ketonization of olefins [75, 76], and the hydroxylation of benzene to phenol, catalyzed by iron containing zeolites [77]. The latter is a good example of the design of an alternative route to a bulk intermediate, viz. phenol [78]. At the moment, phenol is indeed obtained via an acid catalyzed Hock rearrangement of cumene hydroperoxide, co-producing a stoichiometric amount of acetone [1]. Cumene hydroperoxide is obtained by auto-oxidation of cumene, which is synthesized by Friedel-Crafts alkylation of benzene with propene. Substituting this three step process by a direct hydroxylation clearly offers many advantages, more so considering the phenol market is developing faster than the acetone market. This implies that the direct process could reduce overproduction of acetone and save propene. Unfortunately, for large scale applications one has to produce additional $\mathrm{N}_{2} \mathrm{O}$ via oxidation of $\mathrm{NH}_{3}$ with air, leaving behind the original concept of reducing the emission of a greenhouse gas by using it as an oxidant [77]. Nevertheless, for specific applications, the $\mathrm{N}_{2} \mathrm{O}$ produced in $\mathrm{HNO}_{3}$ oxidation plants can be sufficient to open new routes to interesting products. For instance, BASF will start using a fraction of the $\mathrm{N}_{2} \mathrm{O}$ generated in their adipic acid plant for the ketonization of cyclododecatriene, which followed by partial hydrogenation yields cyclododecanone, used in the synthesis of nylon-12 [74, 79, 80].

Other oxidants that are very popular, especially in the field of epoxidations, are $\mathrm{H}_{2} \mathrm{O}_{2}$ and hydroperoxides in general [81-85]. Although $t$-butylhydroperoxide is more active due to a weaker $\mathrm{O}-\mathrm{O}$ bond, it produces equimolar amounts of $t$-butylalcohol as a by-product, whereas $\mathrm{H}_{2} \mathrm{O}_{2}$ only produces water as a by-product. Work has been done to generate $\mathrm{H}_{2} \mathrm{O}_{2}$ in situ via a controlled reaction between $\mathrm{H}_{2}$ and $\mathrm{O}_{2}$. One should however be careful not to violate one of the principles of green chemistry which states that one should design intrinsically safe processes for accident prevention. In the field of epoxidations, one observes the development of metal free epoxidation processes, using $\mathrm{H}_{2} \mathrm{O}_{2}$ [86-90]. This is a nice example of how the catalystoxidant couple can be optimized. Especially in such emerging domains, high-throughput experiments have proven themselves to be very useful in optimizing the catalyst composition. Nevertheless, to bring this further, mechanistic studies using for instance in situ spectroscopy will be required [54-66].

A general problem of the aforementioned oxidants is that they are all generated via the oxidation of a precursor with oxygen. So in the end it is always $\mathrm{O}_{2}$, which takes up the stoichiometric number of electrons. Directly using oxygen (air) as an oxidant would therefore not only reduce the cost, it would also eliminate many environmental problems. Unfortunately the scope of molecular oxygen as an oxidant is at present still narrow [69]. Looking carefully at the most suitable activation mechanism still remains a huge challenge in this area.

\section{Activation Mechanism}

Reactions of ground state molecular oxygen with hydrocarbons are usually very slow, due to the fact that they are 
either spin and/or symmetry forbidden. Therefore one should use an appropriate activation mechanism, compatible with the reactants. Generally speaking, the activation mechanisms can be divided into four different categories, as shown in Fig. 7: thermal activation, "classical" and bio catalysis, electro-catalysis and photo-catalysis.

Problems are not only caused by the substrates kinetic inertness, preventing the over-oxidation of the desired products also provides a significant challenge [1, 3]. As already mentioned above, the desired oxygenated products are more susceptible to oxidation than the alkane substrate, viz. the activation barrier for the consecutive steps is smaller. This situation is shown in the potential energy diagram in Fig. 8 in which B represents the desired product.

When sufficient heat is provided to a hydrocarbon $/ \mathrm{O}_{2}$ mixture, the high-energy spin forbidden pathways can be bypassed by a more efficient free radical mechanism in which peroxyl radicals act as the active oxidant instead of $\mathrm{O}_{2}$ [1, 3]. Although this thermal activation is already industrially applied on a large scale, the precise mechanisms are not yet fully understood. A prerequisite to improve the selectivity is therefore to elucidate the pathways which lead to the products and by-products [91-95]. In the case of for instance cyclohexane autoxidation, cyclohexoxy radicals are formed which can either react with the alkane, generating alcohol, or undergo a uni-molecular $\mathrm{C}-\mathrm{C}$ cleavage reaction, leading to ring-opened by-products [96]. As the activation barrier of the uni-molecular cleavage is higher than that of the bi-molecular channel, high temperatures favor the by-product route.

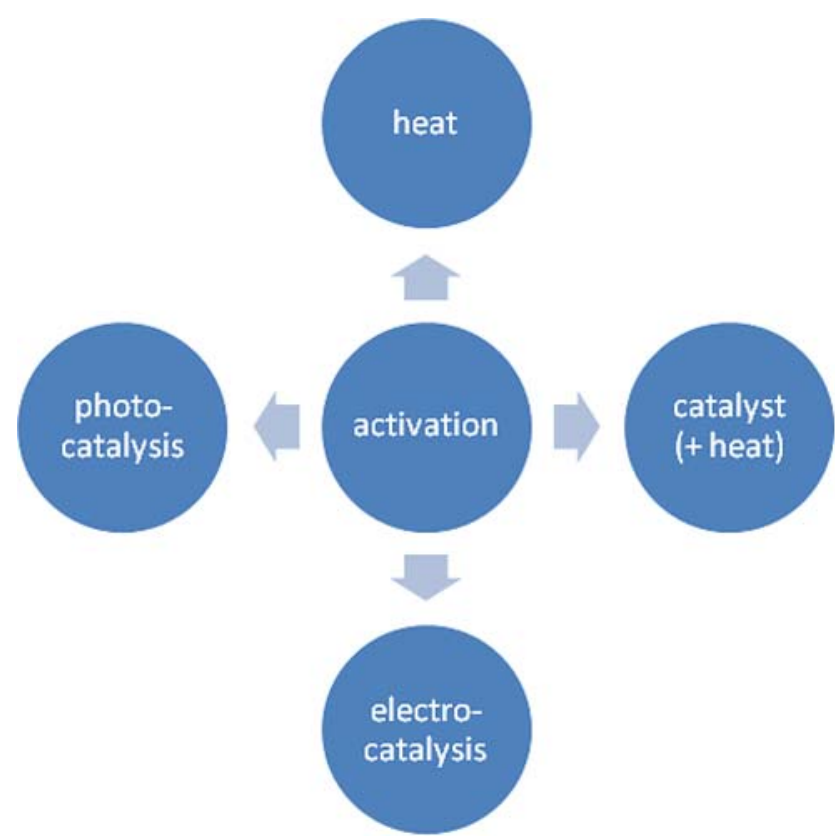

Fig. 7 Different approaches to activate selective oxidations
This is the point at which catalysis and chemical engineering (vide infra) can contribute via various approaches (Fig. 8). One approach could for instance be trapping the reactive intermediate $\mathrm{B}$ and/or converting it to a less reactive product. This trapping can possibly be achieved using a catalyst or via a thermal reaction (viz. protection groups in organic synthesis). Another approach could be to significantly alter the reaction mechanism with a catalyst in such a way that the activation barrier E1 decreases, relative to E2: viz. activate only the desired step A to B (Fig. 8). For autoxidations one could, for instance, try to convert the chain-carrying peroxyl radicals into another type of radical which would result in a better selectivity. One interesting development is the use of $N$-hydroxyphthalimide and related compounds which react with peroxyl radicals to generate $N$-oxyl radicals [97-102]. Using this approach, one might conceivably gain control over the radical chain length and hence the reactivity/selectivity.

Alternatively one could activate $\mathrm{O}_{2}$ at the surface of a heterogeneous catalyst, generating several different activated O-species. However, this requires heating of the system to facilitate (dissociative) $\mathrm{O}_{2}$ adsorption. Generally speaking one distinguishes two types of activated species: Electron deficient electrophilic adsorbed species (superoxide $\mathrm{O}_{2}{ }^{-}$, peroxide $\mathrm{O}_{2}{ }^{2-}$ and oxide $\mathrm{O}^{-}$) and saturated nucleophilic species such as terminal oxygen groups $\mathrm{M}=\mathrm{O}$, or $\mathrm{M}-\mathrm{O}-\mathrm{M}$ where oxygen is in a nominal $\mathrm{O}^{2-}$ state [103-106]. The first class tends to cause over-oxidation whereas the nucleophilic species are assumed to be responsible for selective oxidations. At the moment, however, it is very difficult to quantify all the various species present at the surface and in the sub-surface of a catalyst in action, let alone gain control over their formation. Another approach is to activate the alkane instead of the oxygen such as it is done in the well known Catalytica system [30]. However, these "classical" catalytic approaches, whether homogeneous or heterogeneous, require heat to activate the reaction, after causing the formation of by-products. This is a significant problem in the functionalization of fine chemicals. Especially for this type of demanding transformation, bio-catalysts (viz. enzymes) offer interesting perspectives [107-111].

Redox reactions can also be performed with an electrocatalyst. Although there are some select processes that use electrocatalysis on a large scale (e.g. the hydrodimerization of acrylonitrile to adiponitrile, $300.000 \mathrm{t} / \mathrm{a}$ ), this field has yet to achieve more widespread application [112, 113]. A possible reason for this may be the relative high price of electricity; it is, at present, almost exclusively more efficient to apply heat directly rather than transform the heat into electric current using a generator, and applying the electric current as an activation mechanism. Progress may be made using the recent advances in the field of 
Fig. 8 Potential energy diagram for the selective oxidation of $\mathrm{A}$ to $\mathrm{B}$ with the possibility of over-oxidizing B to C. $E_{1}$ and $E_{2}$ refer to the activation barriers in absence of a catalyst, whereas $E_{1}^{\text {cat }}$ and $E_{2}^{\text {cat }}$ refer to the barriers in presence of a selective oxidation catalyst

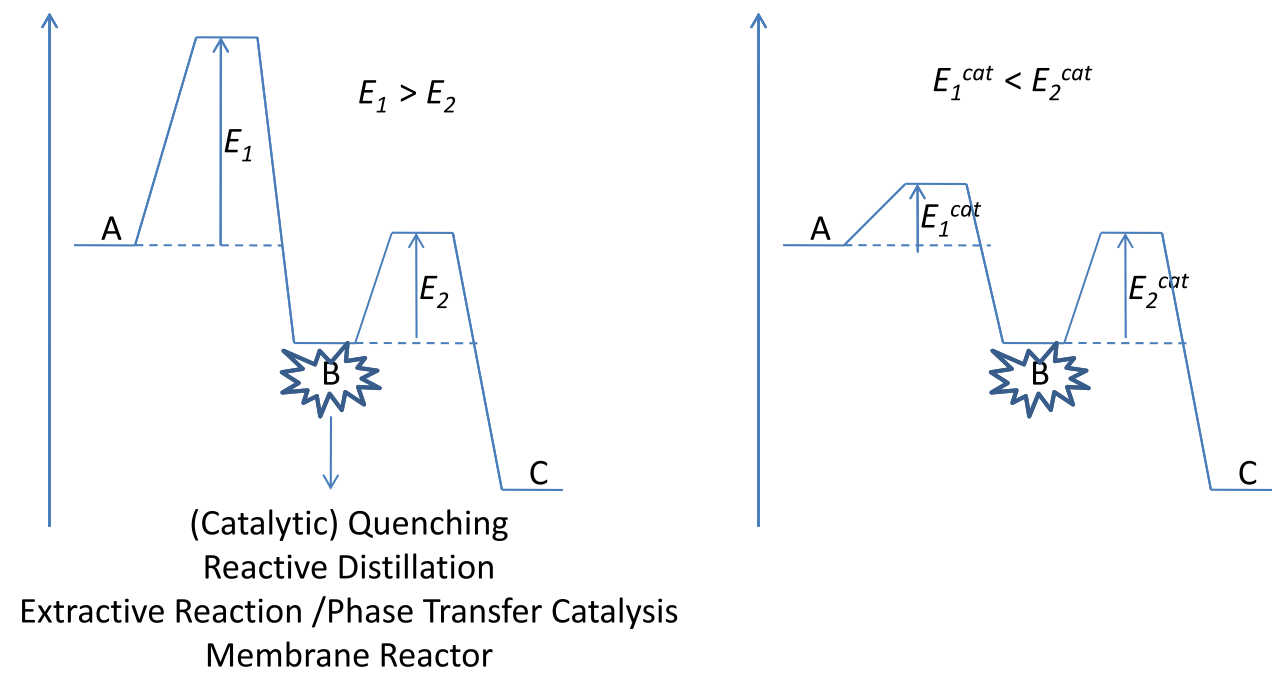

photoelectric cell production. However, as with all applications based on direct electricity generation through sunlight, this idea suffers from both moderate to low efficiency, as well as inconsistency due to varying solar irradiation levels. An interesting approach to this second issue would be the use of recent developments in photocatalysis: coupling a photocatalytic system with a fuel cell would provide an opportunity for constant current generation, and thus increase the feasibility of electrically activated catalytic processes.

In recent years, the application of photocatalysis has generated increasing research interest. The reasons for the heightened awareness with regards to light-catalyzed reactions are many [114]. The use of light allows the introduction of the activation energy necessary for a reaction to proceed, without the problems inherent in thermal energy application; i.e. side reactions, risk associated with high temperatures, higher reactor cost due to high temperature applications, etc. Although photocatalysis is classically used for the decomposition of (volatile) organic compounds (e.g. for water remediation applications or selfcleaning windows), increasing attention is also being focused onto selective reactions. One interesting aspect of photocatalytic reaction systems is that, unlike standard catalyzed reactions, the forward and backward reactions are not necessarily both accelerated, or not accelerated to an equal degree. This implies that photocatalysis can change the apparent thermodynamic equilibrium of a reaction system.

Generally speaking, two principle categories of heterogeneous photocatalysts exist: Semiconductor Photocatalysts and Quantum Photocatalysts. Although operating according to slightly different mechanisms they are both based on the generation of charge-separation [115-117]. Photochemistry applications in selective organic syntheses were exhaustively reviewed by Hoffmann, describing the high potential for photocatalytic oxidations under solar irradiation, using various sensitizing agents [118]. The applicability of photooxidation reactions in an industrial context can be seen using the example of rose oxide. Dragoco in Holzminden, Germany produces $60-100$ t/a of this fragrance, using photooxidation in one of the first steps. Citronellol is oxidized in the presence of sensitizer (Rose Bengal) using molecular oxygen [119]. The resulting hydroperoxides are then reduced to the alcohols, which then are transformed into the corresponding cyclic ethers.

Although photocatalysis provides a number of highly interesting advantages (application under solar irradiation, shifting of the thermodynamic equilibrium, generally lower toxicity and harshness of conditions when compared to the classic thermo-energetic approach), nearly all the systems examined have several shortcomings which hinder their application on a larger scale. Amongst the issues to be addressed are: (i) almost exclusive higher activity of UVirradiation when compared to visible light irradiation, (ii) low conversions of almost all systems, and (iii) low selectivity. The first issue may perhaps be corrected using certain sensitizers, while the second and third problems will require the development of optimized or fully novel reaction systems, so as to provide a feasible alternative to the currently employed approaches. There are, however, selected reaction systems (cfr. rose oxide), which have the theoretic ability to surpass even the more advanced thermally induced catalytic routes using existing technology. The fluctuating intensity of sun light remains however a fundamental engineering problem, causing indeed fluctuations in the production. Nevertheless there is strong belief that for specific applications photocatalysis will future develop and open new horizons, in the domain of selective oxidations and other fields [120-123]. 


\section{Engineering Principles}

Generally speaking, a reaction can be carried out in different states of matter: (i) gas, (ii) liquid, (iii) gas-liquid and (iv) supercritical. Obviously the natures of the feedstock and substrate already predetermine to a great extent the process possibilities. For instance oxidation of small molecules such as methane and propene would demand a high pressure to be performed in the liquid phase, whereas oxidation of bulky fine chemical intermediates might be difficult in the gas phase, mainly because of the low vapor pressure and thermal instability. The use of solvents should be limited as much as possible (cfr. the 12 principles of green chemistry) [124]. Indeed, recycling of the solvent is often an important part of the production cost, not to mention the loss by co-oxidation of solvent (viz. so-called sacrificial solvents). This is for instance the case during the commercial oxidation of $p$-xylene to terephthalic acid, consuming a large part of the global acetic acid production. Moreover, solvents often lead to by-products as it is observed in the recently started propylene epoxidation process with $\mathrm{H}_{2} \mathrm{O}_{2}$ in methanol. The most sustainable solution is to use no solvent, or use the substrate as solvent. Especially for oxidations, $\mathrm{scCO}_{2}$ can offer many advantages such as: (i) dilution of the reaction medium by inert $\mathrm{CO}_{2}$, leading to inherently safer process conditions, (ii) elimination of gas-liquid mass transfer problems, and enhancement of fluid-solid transport [125-130]. Nevertheless, a disadvantage is the rather low throughput per volume, due to the dilution of the substrate with $\mathrm{CO}_{2}$. Additionally, the use of supercritical processes leads to moderately (for $\mathrm{CO}_{2}$ ) or massively (for $\mathrm{H}_{2} \mathrm{O}$ ) increased energy demands, and in the case of $\mathrm{x}_{2} \mathrm{O}$ severe corrosion. The energy gain in the downstream processing must thus be able to compensate for any additional energy expenditure during the reaction. Also ionic liquids (ILs) have been proposed as green solvents, mainly because of their low volatility [131, 132]. Due to their unique properties, ILs might not only work as dissolution media, they might also play a key role in activating the catalyst through coordination and/or intermolecular interactions [133].

It is moreover important to bear in mind that a chemical plant is much more than just the catalytic reactor: also in the (thermal) separation processes, side reactions can occur, reducing the overall performance. On the other hand it is clear that an improvement of the catalyst (viz. reduction of side reactions) can significantly reduce the downstream separations, and hence eventually also reduce side reactions outside the reactor, achieving a synergetic effect.

As was mentioned above, the product being more reactive than the substrate, oxidation reactions have an inherent selectivity problem (viz. $A \stackrel{k_{1}}{\longrightarrow} B \stackrel{k_{2}}{\longrightarrow} C$ with $k_{1}<k_{2}$ ). Analyzing the maximal possible selectivity for both a continuously stirred tank reactor (CSTR), and a plug flow reactor (PFR), as a function of the relative rate constants shows that a PFR will deliver an equal or better maximal yield of product $\mathrm{B}$, whatever the rate constants $[134,135]$. This knowledge is of the utmost significance, as it clearly shows the superiority of a PFR over a CSTR under selectivity considerations. Figure 9 shows the ratio of the maximum yield obtained in a PFR over a CSTR as a function of the relative rate constant $k_{2} / k_{1}$. It can be seen that the relative yield of the product $\mathrm{B}$ may be increased by almost 50\%, depending on the relative reactivities of the product and substrate. The PFR advantage is based on the transient reactant concentration along the reactor axis, compared to a CSTR where the concentration is homogeneous throughout the reactor. However, there are specific cases, where a CSTR may be advantageous due to other considerations such as heat or mass transfer.

Another engineering approach to increase the yield of a desired intermediate product is to separate it in situ from the reaction mixture (reactive separation). However in case of oxidations, the boiling point of the product is usually higher than that of the reactant, implying that reactive distillation is not an option. A feasible approach is to work in a multiphase system in which the product is continuously extracted to another phase where it is protected from subsequent further oxidation (viz. Phase Transfer Catalysis) [136]. Another approach is to use a membrane to continuously remove the product, or to control the contact between the different reactants [137-140]. More recently, membrane reactors have also been used as an in situ nano-filtration system for the retention of catalytic nano-particles [141, 142]. As such, the membrane reactor is used to recycle the catalyst, rather than to influence the product concentration. The membrane can be constructed from either polymers, metals and metal alloys, or solid oxides. Combining the field of heterogeneous catalysis with membrane reactor technology might open new opportunities to improve selective oxidations.

The selectivity of a particular system may also be influenced by the mass transfer properties of the catalyst. Assuming the higher reactivity of the oxidation product, it is apparent that enhanced mass transfer should be beneficial to the specific yield. Through varying the design specifications (size, porosity etc.) of the catalyst particles or the catalyst bed as a whole, it may be possible to greatly influence the product distribution of a given system without changing any of the substrate or oxidant substances involved. The performance of colloids and immobilized nano-particles should therefore be explored in more detail [143-152].

A general problem of oxidations is the exothermicity. Indeed, the heat of reaction needs to be efficiently removed from the reaction medium, in order to avoid a reduction in selectivity or even to prevent a run-away. Industrially this is either achieved through the application of multi-tubular 


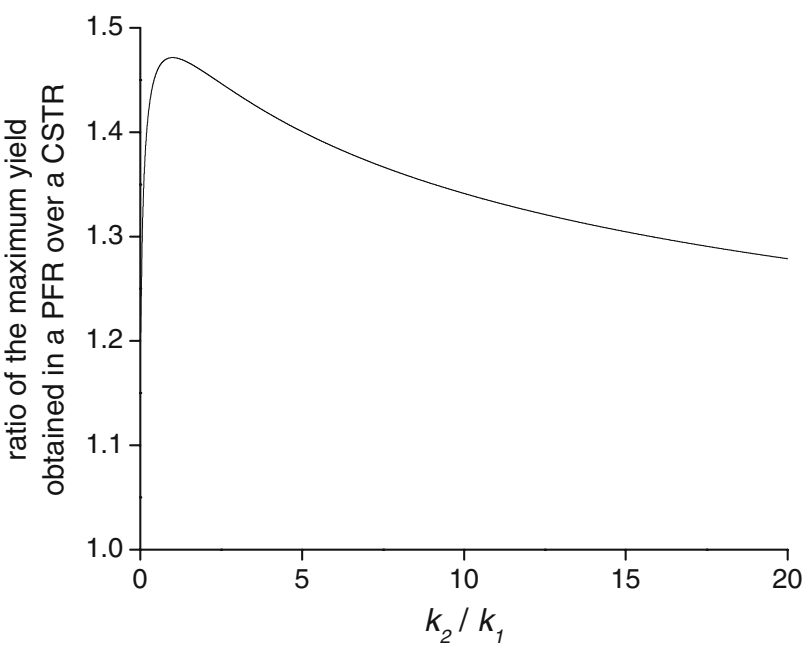

Fig. 9 Ratio of the maximum achievable yield in a desired intermediate of consecutive reactions in a CSTR to a PFR as a function of the rate constant ratio (see text)

reactors which may also serve as heat exchangers, or by using fluidized bed reactors $[134,135]$. In the last decades, this problem prompted the study of process intensification. For instance, micro-reactors could offer interesting prospects to control highly exothermic reactions $[153,154]$. The characteristic dimensions of the internal structures of micro-reactors (MiRs) are typically in the range from sub$\mathrm{mm}$ to even sub- $\mu \mathrm{m}$. Although proposed and tested for the first time in the early 1990s, one observes an intensified research activity in this area in the last couple of years. One of the advantages of MiRs is their possibility to achieve fast and efficient mico-mixing on a time scale of seconds, or even ms. Another big advantage is the improved heat transfer to pressure loss ratio. Due to the high heat transfer coefficients, MiRs can operate under nearly isothermal conditions. Moreover, due to the small size; they not only save space and material, they also lead to an inherently safer process. This even allows for instance operating in the explosion regime: in $300 \mu \mathrm{m} \times 300 \mu \mathrm{m} \times 1 \mathrm{~m}$ channels, cyclohexane could be oxidized with $\mathrm{O}_{2}$ up to $4 \%$ conversion with a selectivity of $88 \%$ in 2 min residence time [155]. Although MiRs were often considered to only offer potential for exploratory studies (cfr. lab-on-a-chip) [156], recent reports announce that the MiR is not just a toy but will soon become a production tool [157].

\section{Conclusions}

In this contribution, we have presented a concise summary of the toolbox available to improve and design novel catalytic oxidation processes. As oxidation catalysis depends to a great extent on the simultaneous developments and advances in multiple disciplines, the field should be approached from different angles, comprising the available feedstock, optimal activation mechanism, suitable oxidant and reactor design.

The feedstock aspect was found to be of major importance for the 21st century. Replacing fossil resources with alternative feedstock will confront us with many challenges. Defining the viability of a certain reaction, allows a concise and rough estimation of the impact a certain alternative feedstock may possibly achieve with regards to resource consumption. Finding suitable oxidants was deemed to be strewn with opportunities and challenges. We described the difficulties involved with applying oxygen as an oxidant directly, and presented the most frequently encountered alternatives. Oxidation reactions can be activated via different approaches, ranging from purely thermal activation to photo-catalysis. Although the latter shows a great deal of promise, it is at present (with few specific exceptions) not feasible to perform (bulk) oxidation processes using exclusively the activation through sunlight. Upon maturation of this technology, however, it might become possible to effectively address many problems facing industrial chemistry, not least of which are the issues of selectivity and energy efficiency. Finally we briefly described some of the most basic and significant reactor design concepts which must be applied when conceptualizing catalytic oxidation processes. The effect of choosing a plug flow reactor over a continuously stirred tank reactor was described, as well as some general considerations which apply to catalytic oxidation (thermal considerations, higher reactivity of the product relative to the substrate). Some of the more promising approaches in reactor design were shown such as supercritical phase reactions, micro- and membrane-reactors. Concerning the emerging photocatalytic systems, new reactor types must be designed to efficiently capture photon energy and transform it into catalytic activity.

The field of oxidation catalysis is a complex one, filled with challenges and opportunities. The solution of any given problem in this field may be achieved through a variety of different paths, as the various parameters involved in catalysis in general and oxidations in particular are intimately linked. For this reason a multi-pronged approach is suggested, taking into account the scientific achievements and advances in a multitude of different disciplines.

Acknowledgments The authors thank ETH Zurich and the Swiss National Science Foundation for their financial contributions. IH acknowledges Pierre Jacobs for his kind help and support during his time at K.U.Leuven.

\section{References}

1. Franz G, Sheldon RA (2005) Oxidation, Ullmann's encyclopedia of industrial chemistry. Wiley-VCH, Weinheim 
2. Wittcoff HA, Reuben BG, Plotkin JS (2004) Industrial organic chemicals. Wiley-Interscience, New Jersey

3. Sheldon RA, Kochi JK (1981) Metal-catalyzed oxidations of organic compounds. Academic Press, New York

4. Anastas PT, Warner JC (2000) Green chemistry: theory and practice. Oxford University Press, New York

5. Clark J, Macquarrie D (2002) Handbook of green chemistry \& technology. Blackwell Publishing, Oxford

6. Knözinger H, Kochloefl K (2005) Heterogeneous catalysis and solid catalysts, Ullmann's encyclopedia of industrial chemistry. Wiley-VCH Verlag GmbH \& Co. KGaA, Weinheim

7. Ertl G, Knözinger H, Weitkamp J (1999) Preparation of sold catalysts. Wiley-VCH, Weinheim

8. Paul JS, Urschey J, Jacobs PA, Maier WF, Verpoort F (2003) J Catal 220:136

9. Paul JS, Groothaert MH, Kirchhock CEA, Lebedev OI, Jacobs PA, Maier WF (2004) Catal Today 91-92:265

10. Grasselli RK, Lugmair CG, Volpe AF Jr (2008) Top Catal 50:66

11. Brazdil JF (2006) Top Catal 38:289

12. Bravo-Suarez JJ, Bando KK, Lu JQ, Fujitani T, Oyama ST (2008) J Catal 255:114

13. Hess C, Looi MH, Abd Hamid SB, Schlögl R (2006) Chem Commun $4: 451$

14. Thomas JM, Raja R (2006) Catal Today 117(1-3):22

15. Raja R, Thomas JM, Xu M, Harris KDM, Greenhill-Hooper M, Quill K (2006) Chem Commun 4:448

16. Thomas JM, Raja R, Sankar G, Bell RG (2001) Acc Chem Res 34:191

17. Raja R, Sankar G, Thomas JM (2000) Angew Chem Int Ed 39:2313

18. Thomas JM (2008) Top Catal 50:98

19. Thomas JM, Raja R (2005) PNAS 102:13732

20. Moden B, Zhan BZ, Dakka J, Santiesteban JG, Iglesia E (2007) J Phys Chem C 111:1402

21. Zhan BZ, Moden B, Dakka J, Santiesteban JG, Iglesia E (2007) J Catal 245:316

22. Chynoweth DP, Owens JM, Legrand R (2000) Renewable Energ 22:1

23. Crabtree RH (1995) Chem Rev 95:987

24. Conley BL, Tenn WJ, Young KJH, Ganesh S, Meier S, Ziatdinov V, Mironov O, Oxgaard J, Gonzales J, WA Goddard III, Periana RA (2006) In: Tolman WB (ed) Activation of small molecules. Wiley-VCH

25. Shilov AE, Shul'pin GB (1997) Chem Rev 97:2879

26. Lersch M, Tilset M (2005) Chem Rev 105:2471

27. Díaz-Requejo MM, Pérez PJ (2008) Chem Rev 108:3379

28. Olah GA (1987) Acc Chem Res 20:422

29. Arena F, Parmaliana A (2003) Acc Chem Res 36:867

30. Periana RA, Taube DJ, Gamble S, Taube H, Satoh T, Fujii H (1998) Science 280:560

31. Conley BL, Ganesh SK, Gonzales JM, Ess DH, Nielsen RJ, Ziatdinov VR, Oxgaard J, Goddard WAIII, Periana RA (2008) Angew Chem Int Ed 47:7849

32. Haw JF, Song W, Marcus DM, Nicholas JB (2003) Acc Chem Res 36:317

33. Khodakov AY, Chu W, Fongarland P (2007) Chem Rev 107: 1692

34. Biermann U, Friedt W, Lang S, Lühs W, Machmüller G, Metzger JO, genKlaas MR, Schäfer HJ, Schneider MP (2000) Angew Chem Int Ed 39:2206

35. Gallezot P (2007) In: Centi G, van Santen RA (eds) Catalysis for renewables, chap. 3. Wiley-VCH Verlag GmbH \& Co. KGaA, Weinheim

36. Corma A, Iborra S, Velty A (2007) Chem Rev 107:2411

37. Blas J (2008) UN food agency in warning over harm caused by biofuel growth. Financial Times, 8th October
38. Rostrup-Nielsen JR (2000) In: Derouane EG (ed) Combinatorial catalysis and high throughput catalyst design and testing, vol 560. NATO ASI Science series C, Kluwer Academic Publishers, Dortrecht, p 337

39. Sels B, D'Hondt E, Jacobs P (2007) In: Centi G, van Santen RA (eds) Catalysis for renewables: from feedstock to energy production, chap. 11. Wiley-VCH, Weinheim

40. Behr A, Eilting J, Irawadi K, Leschinski J, Lindner F (2008) Green chem 10:13

41. Zheng Y, Chen X, Shen Y Chem Rev. doi:10.1021/cr068216s

42. Huber GW, Iborra S, Corma A (2006) Chem Rev 106:4044

43. Kunkes EL, Simonetti DA, West RM, Serrano-Ruiz JC, Gärtner CA, Dumesic JA (2008) Science 322:417

44. Service RF (2008) Science 322:522

45. Román-Leshkov Y, Chheda JN, Dumesic JA (2006) Science 312:1933

46. Huber GW, Chheda JN, Barrett CJ, Dumesic JA (2005) Science 308:1446

47. Stöcker M (2008) Angew Chem Int Ed 47:2

48. Chheda JN, Huber GW, Dumesic JA (2007) Angew Chem Int Ed 46:7164

49. Holmgren J, Marinangeli R, Marker T, McCall M, Petri J, Czernik S, Elliott D, Shonnard D (2007) Hydrocarbon Eng

50. Holmgren J, Gosling C, Marinangeli R, Marker T, Faraci G, Perego C (2007) Hydrocarbon Process 86:67

51. Kalnes T, Marker T, Shonnard DR, Koers KP (2008) Biofuels Q4:7

52. Pinna CD, Falletta E, Prati L, Rossi M (2008) Chem Soc Rev 37:2077

53. Menini L, Pereira MC, Parreira LA, Fabris JD, Gusevskaya EV (2008) J Catal 254:355 and references therein

54. Poliakoff M, Howdle SM, Kazarian SG (1995) Angew Chem Int Ed Engl 34:1275

55. Grunwaldt JD, Wandeler R, Baiker A (2003) Catal Rev Sci Eng 45:1

56. Weckhuysen BM (2003) Phys Chem Chem Phys 5:4351

57. Keresszegi C, Grunwaldt JD, Mallat T, Baiker A (2003) Chem Commun 2304

58. Bruckner A (2003) Catal Rev Sci Eng 45:97

59. Grunwaldt JD, Baiker A (2005) Phys Chem Chem Phys 7:3526

60. Bell AT (2008) Nature 456:185

61. Nijhuis TA, Sacaliuc E, Beale AM, van der Eerden AMJ, Schouten JC, Weckhuysen BM (2008) J Catal 258:256

62. Goodrow A, Bell AT (2008) J Phys Chem C 112:13204

63. Weckhuysen BM (2004) In situ spectroscopy of catalysts. American Scientific Publishers, Stevenson Ranch

64. Bürgi T, Baiker A (2006) Adv Catal 50A:229

65. Hunger M, Weitkamp J (2001) Angew Chem Int Ed 40: 2955

66. Imbihl R, Scheibe A, Zeng YF, Günther S, Kraehnert R, Kondratenko VA, Baerns M, Offermans WK, Jansen APJ, van Santen RA (2007) Phys Chem Chem Phys 9:3522

67. Maslow AH (1943) Psych Rev 50:370

68. Mecking S (2004) Angew Chem Int Ed 43:1078

69. Beller M (2004) Adv Synth Catal 346:107

70. Sheldon RA (1992) Chem Int 23:903

71. Sheldon RA (1996) J Mol Catal A Chem 107:75

72. Sheldon RA (2000) Chem Rev 9:10

73. Sheldon RA (2007) Green Chem 9:1273

74. Teles JH (2008) In: 10th international symposium on the activation of dioxygen and homogeneous catalytic oxidation. ADHOC, Venice

75. Starokon EV, Dubkov KA, Babushkin DE, Parmon VN, Panov GI (2004) Adv Synth Catal 346:268

76. Hermans I, Janssen K, Moens B, Philippaerts A, Van Berlo B, Peeters J, Jacobs PA, Sels BF (2007) Adv Synth Catal 349:1604 
77. Parmon VN, Panov GI, Uriarte A, Noskov AS (2005) Catal Today 100:115

78. Sayyar MH, Wakeman RJ (2008) Chem Eng Res Des 86:517

79. Teles JH, Rossler B (2004) WO2004096745-A1 (BASF AG)

80. Teles JH, Rossler B, Pinkos R, Genger T, Preiss T (2004) WO2005030689-A2 (BASF AG)

81. Arts SJHF, Mombarg EJM, van Bekkum H, Sheldon RA (1997) Synthesis 6:597

82. De Vos DE, Sels BF, Jacobs PA (2003) Adv Synth Catal 345:457

83. Dusi M, Mallat T, Baiker A (2000) Catal Rev Sci Eng 42:213

84. De Vos DE, Dams M, Sels BF, Jacobs PA (2002) Chem Rev 102:3615

85. Oyama ST (2008) Mechanisms in homogeneous and heterogeneous epoxidation catalysis. Elsevier, Amsterdam

86. Mandelli D, van Vliet MCA, Sheldon RA, Schuchardt U (2001) Appl Catal A 219:209

87. van Vliet MCA, Mandelli D, Arends IWCE, Schuchardt U, Sheldon RA (2001) Green Chem 3:243

88. Rinaldi R, Sepffllveda J, Schuchardt U (2004) Adv Synth Catal 346:281

89. Rinaldi R, Schuchardt U (2004) J Catal 227:109

90. Pescarmona PP, Janssen KPF, Jacobs PA (2007) Chem Eur J 13:6562

91. Hermans I, Nguyen TL, Jacobs PA, Peeters J (2005) Chem Phys Chem 6:637

92. Hermans I, Jacobs PA, Peeters J (2006) J Mol Catal A Chem 251:221

93. Hermans I, Jacobs PA, Peeters J (2006) Chem Eur J 12:4229

94. Hermans I, Peeters J, Vereeckenn L, Jacobs P (2007) Chem Phys Chem 8:2678

95. Hermans I, Peeters J, Jacobs P (2007) J Org Chem 72:3057

96. Hermans I, Jacobs PA, Peeters J (2007) Chem Eur J 13:754

97. Ishii Y, Sakaguchi S (1999) Catal Surv Jpn 3:27

98. Ishii Y, Sakaguchi S, Iwahama T (2001) Adv Synth Catal 343:393

99. Hermans I, Vereecken L, Jacobs PA, Peeters J (2004) Chem Commun 1140

100. Sheldon RA, Arends IWCE (2006) Mol Catal A Chem 251:200

101. Hermans I, Jacobs P, Peeters J (2007) Phys Chem Chem Phys 9:686

102. Recupero F, Punta C (2007) Chem Rev 107:3800

103. Grasselli RK (1997) In: Ertl G, Knözinger H, Weitkamp J (eds) Handbook of heterogeneous catalysis, vol 5. Wiley-VCH, Weinheim

104. Grasselli RK (1999) Catal Today 49:141

105. Grasselli RK (2002) Top Catal 21:79

106. Mizuno N (2008) Modern heterogeneous oxidation catalysis: design, reactions and characterization. Wiley. ISBN: 978-3-52731859-9

107. Sheldon RA (2008) Chem Commun 29:3352

108. Sheldon RA (2007) Adv Synth Catal 349:1289

109. Schramm VL (2006) Chem Rev 106:3029

110. De Wildeman SMA, Sonke T, Schoemaker HE, May O (2007) Acc Chem Res 40:1260

111. Sheldon RA, van Rantwijk F (2004) Aust J Chem 57:281

112. Lipkowski J, Ross P (1998) Electrocatalysis. Wiley-VCH, Weinheim

113. Wendt H, Vogt H, Kreysa G, Kolb DM, Engelmann GE, Ziegler JC, Goldacker H, Jüttner K, Galla U, Schmieder H, Steckhan E (2005) Electrochemistry, Ullmann's encyclopedia of industrial chemistry. Wiley-VCH, Weinheim

114. Fox MA, Dulay MT (1993) Chem Rev 93:341

115. Yuliati L, Yoshida H (2008) Chem Soc Rev 37:1592

116. Arakawa H, Sayama K (2000) Res Chem Int 26:145
117. Yoshida H (2003) Curr Opin Solid State Mater Sci 7:435

118. Hoffmann N (2008) Chem Rev 108:1052

119. Monnerie N, Ortner J (2001) J Sol Energy Eng-Trans Asme 123:171

120. Yeom YH, Frei H (2002) J Phys Chem A 106:3350

121. Lin WY, Frei H, Phys J (2005) Chem B 109:4929

122. Frei H (2006) Science 313:309

123. Mul G, Wasylenko W, Hamdy MS, Frei H (2008) Phys Chem Chem Phys 10:3131

124. Sheldon RA (2005) Green Chem 7:267

125. Baiker A (1999) Chem Rev 99:453

126. Caravati M, Grunwaldt JD, Baiker A (2006) App Catal A Gen 298:50

127. Matsuda T, Harada T, Nakamura K (2005) Curr Org Chem 9:299

128. Kasnevich AD, Beckman EJ (2004) Chim Oggi Chem Today 22:38

129. Beckman EJ (2003) Environ Sci Technol 37:5289

130. Jin H, Subramaniam B (2003) Chem Eng Sci 58:1897

131. Sheldon RA (2001) Chem Commun 2399

132. Welton $\mathrm{T}$ (2004) Coord Chem Rev 248:2459

133. Cheng J, Li Z, Haught M, Tang Y (2006) Chem Commun 4617

134. Levenspiel O (1999) Chemical reaction engineering. Wiley, New Jersey

135. Froment GF, Bischoff KB (1990) Chemical reactor analysis and design. Wiley, New York

136. Halpern M (2005) Phase-transfer catalysis, Ullmann's encyclopedia of industrial chemistry. Wiley-VCH, Weinheim

137. Miachon S, Dalmon J-A (2004) Top Catal 29:59

138. Oyama ST, Zhang X, Lu J, Gu Y, Fujitani T (2008) J Catal 257:1

139. Bravo-Suárez JJ, Bando KK, Fujitani T, Oyama ST (2008) J Catal 257:32

140. Oyama ST, Hightower JW (1993) Catal Selective Oxid 523:427

141. Mertens PGN, Vankelecom IFJ, Jacobs PA, De Vos DE (2005) Gold Bull 38:157

142. Mertens P, Bulut M, Gevers L, Vankelecom I, Jacobs P, De Vos D (2005) Cat Lett 102:57

143. Henglein A, Ershov BG, Malow M (1995) J Phys Chem 99:14129

144. Roucoux A, Schulz J, Patin H (2002) Chem Rev 102:3757

145. Breynaert E, Hermans I, Lambie B, Maes G, Peeters J, Maes A, Jacobs P (2006) Angew Chem Int Ed 45:7584

146. Narayanan R, El-Sayed MA (2007) Nano Lett 4:1343

147. Ahmadi TS, Wang ZL, Green TC, Henglein A, El-Sayed MA (1996) Science 272:1924

148. Zhang Y, Grass ME, Kuhn JN, Tao F, Habas SE, Huang W, Yang P, Somorjai GA (2008) J Am Chem Soc 130:5868

149. Narayanan R, Tabor C, El-Sayed MA (2008) Top Catal 48:60

150. Hutchings GJ (2008) Dalton Trans 41:5523

151. Haider P, Kimmerle B, Krumeich F, Kleist W, Grunwaldt JD, Baiker A (2008) Catal Lett 125:169

152. Park JY, Lee H, Renzas JR, Zhang YW, Somorjai GA (2008) Nano Lett 8:2388

153. Ehrfeld W, Hessel V, Löwe H (2000) Microreactors. WileyVCH Verlag GmbH \& Co. KGaA, Weinheim

154. Ehrfeld W, Hessel V, Haverkamp V (2005) Microreactors, Ullmann's Encyclopedia of Industrial Chemistry. Wiley-VCH, Weinheim

155. Leclerc A, Alamé M, Schweich D, Pouteau P, Delattre C, de Bellefon C (2008) Lab Chip 8:814

156. Yi JP, Fan ZG, Jiang ZW, Li WS, Zhou XP (2007) J Comb Chem 9:1053

157. Short PL (2008) C\&EN October 20:37 